\title{
Quality, Perceived Usefulness, User Satisfaction, and Intention to Use: An Empirical Study of Ubiquitous Personal Robot Service
}

\author{
Yoojung $\mathrm{Kim}^{1} \&$ Hyung Seok Lee ${ }^{2}$ \\ ${ }^{1}$ Division of Digital Business, Hoseo University, Cheonan, South Korea \\ ${ }^{2}$ Faculty of Business Administration, Chungbuk National University, Cheongju, South Korea \\ Correspondence: Hyung Seok Lee, Faculty of Business Administration, Chungbuk National University, 53 \\ Naesudong-ro Heungdeok-gu, Cheongju Chungbuk 361-763, South Korea. Tel: 82-43-261-3743. E-mail: \\ hyunglee@cbnu.ac.kr
}

Received: April 6, 2014 Accepted: April 28, 2014 Online Published: May 29, 2014

doi:10.5539/ass.v10n11p1 URL: http://dx.doi.org/10.5539/ass.v10n11p1

\begin{abstract}
This study illustrates the acceptance behaviour of ubiquitous personal robot services in Korea on the basis of the previous researches on service quality, systems quality, and technology adoption. We especially build the dimensions of service quality fit for personal robot service characteristics, i.e. tangible quality and motion quality. 490 respondents collected from surveys of Korean households, who used the personal robot in their home for 4 months before the survey, were used to verify the research model. The findings reveal that perceived usefulness and user satisfaction significantly positively impact intention to use a personal robot service. Additionally, perceived usefulness has a far more significant effect on the intention to use the service than does user satisfaction. The service quality was determined to be a significant antecedent of both perceived usefulness and user satisfaction. The most influential factor was the motion quality of the ubiquitous personal robot, followed by tangible quality. System quality proved to be a major determinant of perceived usefulness and user satisfaction, and to have strong effect on perceived usefulness than service quality.
\end{abstract}

Keywords: ubiquitous personal robot, quality, perceived usefulness, user satisfaction

\section{Introduction}

The technology of digital convergence has enabled many countries to provide their consumers with a variety of ubiquitous services including home networking and telematics. The Korean government implemented the IT839 strategy, in 2004, which aims to introduce world's first services and products: introducing and promoting eight services, building three infrastructures, and developing nine ICT (information and communication technology) new growth engines (Chung, 2004). The URC (ubiquitous robot companion), one of the nine specified growth engines, is an IT-based service robot project with the vision involving the use of personal robot services anywhere, anytime. This project focuses on offering robot services that allow users to access intelligent Internet/Web services and perform certain tasks conducted by humans.

The IDC estimated that the intelligent robot service market would increase by almost a hundred-fold between 2003 and 2012, from $\$ 831$ million to $\$ 84.5$ billion (Byun, 2006). The Korean government and institute and agency of science technology have been collaborating on a variety of URC projects for a number of years. The ETRI (Electronics and Telecommunications Research Institute) has been developing major robotic technologies in cooperation with robotics companies. The NIA (National Information Society Agency) has performed a critical function in providing personal robot pilot services focused on identifying the personal robot services adoption behavior of potential consumers by deploying prototype robots in private homes. The services are comprised of interactive, emotional, and intelligent services, including games, home cleaning, children's entertainment, ordering groceries, remote home monitoring, story-telling, and singing.

The robot is a brand-new manifestation of a personal web-based medium by numerous convergent and intelligent information technologies integrated. Physical features and emotion expressions will be the core functions of the robot, because people are anticipating a robot that acts and feels like a human. However, as current robot services fall far short of what users might expect, owing to the lack of adequate technology and the high production cost, it may be difficult and challenging to fulfill users' expectations of quality. Therefore, identifying 
users' perceived quality of the personal robot is critical for pilot services in order to assess the level of acceptance of personal robots at home (Delone \& McLean, 2003; Pitt et al., 1995; Shih, 2004) and reduce the gap between what the users expect and what service can be provided from the personal robot services. Additionally, it would be very valuable to determine the manner in which quality factors affect the acceptance of personal robots. A number of previous studies, grounded on the DeLone and McLean (1992)'s IS success model and the Davis (1989)'s TAM (technology acceptance model), have assessed the factors influencing usage of IS and Internet/Web-based services including e-shopping malls, Internet banking and websites. The information quality, system quality, and service quality of the IS success model have been employed previously to assess the performance and efficacy of IS and Internet/Web services (Aladwani \& Palvia, 2002; Delone \& McLean, 2004; Pitt et al., 1995,). The belief factors (perceived usefulness and perceived ease of use) of TAM have been validated as the determinants of intention to use and actual usage in a number of IS and Internet/Web acceptance studies (Kim et al., 2007; Shih, 2004; Venkatesh \& Morris, 2000). Some have employed IS success dimensions such as information quality, system quality, and service quality as extended factors to identify the effects of those factors on users' belief, as well as the mediating effects of users' belief on users' acceptance behavior (Ahn et al., 2004; Shih, 2004). However, personal robot service is associated with a certain context and some different characteristics from those of previous IS and Internet services, in terms of helping house-working convergent, intelligent, and emotional features. And, the quality factors and measurements employed in previous studies are somewhat insufficient to explain in the quality dimensions of personal robot services. The purpose of this study is twofold: one is to identify and illustrate the quality factors in a more specific and relevant way to elucidate users' perceived quality for commercial products based on previous research into the IS success model and the TAM. The other is to examine the causal relationships among quality factors, perceived usefulness, user satisfaction and the intention to use.

\section{Theoretical Background and Hypothesis}

Delone and McLean (1992) stated in the IS success model that information quality and system quality are the principal predictors for the use of IS. In addition, they maintained that the use of IS influences the user satisfaction with IS, which is in turn the major factor determining the performance of both individuals and organizations. Seddon (1997), however, proposed a different IS success model, insisting that IS use alone is insufficient to explain the success of IS, and rather simply assesses an individual's behavior toward IS. His IS success model includes the factors such as information quality, system quality, perceived usefulness, user satisfaction, and net benefits. Rai et al. (2002) provided empirical verification that the IS success model of DeLone and McLean (1992) and Seddon (1997) is the primary research construct and factor that explains the use and performance of IS. Moreover, many studies regarding the use and performance of IS in an organization have elucidated that information quality and system quality are the main factors influencing the use of IS (Etezadi-Amoli \& Farhoomand, 1996; Igbaria, 1997; Li, 1997).

As end-user computing has been activated and the functions of IS have been decentralized since the mid-1980s, the service quality of IS has been generally regarded to be the critical determinant of the use and success of IS. Thus, a range of studies into the IS success model have derived the ideal service quality factors and measurement items for an optimal IS environment based on SERVQUAL (tangibles, reliability, responsiveness, assurance, and empathy) as proposed by Parasuraman et al. (1988), and these studies have also confirmed the relationship between service quality and IS success (Kettinger \& Lee, 1994; Pitt et al., 1995; Li, 1997; Wilkin \& Hewitt, 1999). In addition, the IS success model began to be employed in research regarding the use and adoption of the Internet/Web for e-commerce (e.g. Internet banking and e-shopping malls) beginning in the late 1990s (Bell \& Tang, 1998; Huizingh, 2000). Delone and McLean $(2003,2004)$ added service quality to the traditional factors of the classical IS success model - information quality, system quality, use, intention to use, user satisfaction, and net benefits - and updated the measurement items in accordance with the e-Commerce context. Additionally, in studies conducted on the website quality model, the service quality dimensions and measurement items have been developed and verified for the purposes of generalization (Aladwani \& Palvia, 2002; McKnight et al., 2002).

The TAM developed by Davis (1989) has been most frequently utilized in explaining the use and use behavior of information technology. Davis (1989) asserted that the usefulness and ease of use significantly influence the attitude toward the usage of information systems; in his theory, this attitude influences the intention to use in relation to the actual use of the system, and the behavior intention in turn influences the actual use of information systems. During the 1990s, many attempts were made to generalize the model by expanding a variety of variables and applying new technologies on the basis of TAM (Karahanna et al., 1999; Lucas \& Spitler, 1999; Venkatesh \& Morris, 2000). The previous studies were predicated on the assertion that various and complicated 
factors, such as individual motivations, that may influence the adoption of a technology, as well as the "usefulness" and "ease of use" factors proposed in the TAM, should be evaluated. Recent studies in this field have focused on the development of TAM models customized specifically to web-based industry on the old factors utilized in the traditional TAM models and the new ones emerging in the Internet environment. Furthermore, research into the combination of online and offline factors as well as the use and adoption of Internet/Web service began to permit a more multidimensional and systematic perspective via the integration of the TAM and the IS success model (Ahn et al., 2004; Shih, 2004).

On the basis of this review of the literature we therefore explore the consumers' adoption behavior of ubiquitous personal robot services being driven by Korean government. Specially, this study aims at the relations between quality factors, perceived usefulness, and user satisfaction, which are expected to have direct or indirect effects on intention to use the services. Considering that URC personal robot service is currently in its pilot service stage and is not yet commercially accessible, service quality focused on performance quality and tangible quality as its primary operating characteristics (Garvin, 1987; Parasuraman et al., 1988).

Perceived usefulness is the most essential factor in the acceptance of the URC personal robot service; users will intend to use the commercial URC personal robot service if they perceive the service to be sufficiently useful, as they expect a great deal from it, and the robot terminal costs a great deal. User satisfaction is the desired emotional attitude toward the URC personal robot service and positive emotion will be the principal factor in individuals' acceptance of the robots. The usefulness of and user satisfaction with the URC personal robot will be affected significantly by both service quality and system quality. The service should be offered on the basis of the specific hardware and software platform possessed by the robot. Thus, with regard to the URC personal robot service, we employed the three dimension of service quality fit for its characteristics; tangibles, responsiveness, and assurance. Tangibles including the Web and physical appearance of the robot platform, responsiveness including free and exuberant motions and diverse driving methods, and assurance including stable and reliable service. In addition, system quality including the information-processing characteristics of the entire URC system such as robot platform, network and URC server will play crucial roles in the user's behavior toward his or her robot. We, however, excluded perceived ease of use from this research, largely because it only indirectly affects the use of information technology, according to several researchers (Davis et al., 1989, Davis, 1989; Mathieson, 1991; Taylor \& Todd, 1995).

\subsection{Perceived Usefulness, User Satisfaction, and Intention to Use}

Perceived usefulness refers to "the degree to which a person believes that using a particular system would enhance his or her job performance" (Davis, 1989). Davis et al. (1989) also previously identified usefulness as the most powerful predictive variable in information technology usage. Since that time, a variety of studies focused on TAM have demonstrated that perceived usefulness is the key determinant factor in cases in which users intend to use a new IS or Internet technology (Adams et al., 1992; Ahn et al, 2004; AL-Gahtani \& King, 1999; Davis et al., 1989; Dishaw \& Strong, 1998; Mathieson, 1991).

According to Doll and Torkzadeh (1988), user satisfaction is "the affective attitude towards a specific computer application of someone who interacts with the application directly". Additionally, Seddon and Kiew (1994) defined user satisfaction as "the net feeling of pleasure or displeasure that results from aggregating all the benefits that a person hopes to receive from interaction with the information systems". Seddon (1997) defines user satisfaction as "a subjective evaluation of the various consequences (individual, organizational, social consequences of IS use) evaluated on a pleasant-unpleasant continuum".

User satisfaction has proven useful in evaluating the effects of IS and Internet/Web systems, and has also been identified as the principal factor in intention to use a new technology (Negasha et al., 2003; Yoon et al., 1995). DeLone and McLean (2003) asserted that user satisfaction with the system influences intention to use, which becomes substantially stronger if the personal, group or organizational performance is improved after the system is used. In addition, they selected user satisfaction as the attitude variable and revealed that user satisfaction is related with both intention to use and usage (Bhattacherjee, 2001; Cenfetelli et al., 2005; Konradta et al., 2006; Mathieson, 1991).

Meanwhile, in cases in which users can improve productivity or performance in their job by using a system, they tend to evidence a positive emotional response to the system. This means that perceived usefulness works very favorably in terms of user satisfaction (Gelderman, 1998). Seddon and Kiew (1994) asserted that perceived usefulness is predictive of user satisfaction and Rai et al. (2002) actually verified the positive relationship between the perceived usefulness of and user satisfaction with the ERP system. Hsu and Chiu (2004) identified perceived usefulness as the determinant factor of user satisfaction in their research on the factors and beliefs that 
affect the constant use of e-service. Cenfetelli et al. (2005) regarded customer service features and tools offered through IT in the e-business environment as functionality, and verified that this functionality is the precedent factor of usefulness and user satisfaction; in that study, they also asserted that usefulness positively influences user satisfaction.

As to the URC personal robot service, the target of this research, users seek values distinctly different from existing IS and Internet services. The robot, which is expected to provide intelligent functions and service, is trusted to act and respond as much like a human being as possible. It is also trusted to do household chores including cleaning, to learn and become smarter, and to offer personalized service virtually anywhere, anytime within the home. Therefore, when users perceive the robot to actually possess the abovementioned values and usefulness through their experiences, they will tend to have a positive intention to use the URC personal robot service. In particular, because of the relatively high price of the URC personal robot, the usefulness perceived by users will be a more powerful influence on intention to use. In short, after a robot is evaluated, the perceived usefulness of the robot will vary directly with user satisfaction, and the user satisfaction will vary directly with intention to use the home robot service. In addition, user satisfaction, which is defined basically as an affective attitude towards the personal robot service by a user who interacts with the personal robot directly, will directly influence the user's intention to use it.

On the basis of the discussion above, the hypothesis of the relationship among perceived usefulness, user satisfaction, and intention to use the URC personal robot service can be asserted as follows:

H1: The perceived usefulness is positively related to the user's intention to use the URC personal robot service.

$\mathrm{H} 2$ : The user satisfaction is positively related to the user's intention to use the URC personal robot service.

H3: The perceived usefulness is positively related to the user's satisfaction with the URC personal robot service.

\subsection{Service Quality, Perceived Usefulness, and User Satisfaction}

Service quality is generally defined as the consumer's perception arising after comparing the customer's perception of the actual service performance (Grönroos, 1984) and the expectation of customer service, or as "a global judgment, or attitude, relating to the superiority of the service" (Parasuraman et al., 1988).

As for the measurement model for service quality, the SERVQUAL model, developed initially by Parasuraman et al. (1988) is routinely used. The SERVQUAL model is composed of 22 items in five dimensions; tangibles, reliability, responsiveness, assurance, and empathy. Tangibles refers to "physical facilities, equipment, and appearance of personnel"; reliability is "ability to perform the promised service dependably"; responsiveness is "willingness to help customers and provide prompt service"; assurance is "knowledge and courtesy of employees and their ability to inspire trust and confidence"; and empathy refers to "Caring, individualized attention the firm provides its customers".

The SERVQUAL model has been utilized as a measurement tool in a variety of industries, including hotel, tourism, department stores, and flight, for more than two decades--it has also been identified as one of the key determinants of satisfaction (Lassar et al., 2000; O'neill et al., 2001; Robldo, 2001). Additionally, it has been applied to IS and Internet/Web systems to measure the service quality of ERP, e-commerce, Internet shopping malls, and websites, and is used in studies regarding the relationship among service quality, satisfaction, and usefulness (Jiang et al., 2000; Lee \& Lin, 2005; Parasuraman et al., 2005; Pitt et al., 1995; Sullivan \& Walstrom, 2001; Van Dyke et al., 1999). Sullivan and Walstrom (2001) have measured the service quality of web-based book dealers using the five dimensions of SERVQUAL and Barnes and Vidgen (2001) have developed the WebQual measurement model after modifying SERVQUAL in accordance with the context of websites on the basis of a previous study. Besides, the service quality measurement items were developed to more accurately characterize the e-service and Internet service environments in a variety of previous studies (Aladwani \& Palvia, 2002; Iwaarden et al., 2004; Liu \& Arnett, 2000; McLean \& DeLone, 2004). DeLone and McLean (2004) developed an IS success model appropriate for e-commerce applications, and selected service quality as the most influential factor in user satisfaction, because the user of e-commerce is not the staff of the organization, but the general user and customer. Moreover, Landrum et al. (2007) compared the service quality measurement items of Magal (1991) and the SERVPERF service quality model, concluding that the measurement items of both models are the major precedent factors of user satisfaction and usefulness.

Meanwhile, research into the adoption of information technology based on TAM has generally found that service quality is far more important when users perceive the usefulness of an IS or Internet/Web system. The service quality in delivery time, reliability, and responsiveness in web-based e-shopping has a high degree of relevance to the usefulness of e-shopping (Ahn et al., 2004; Shih, 2004). 
In the case of the URC personal robot service, the robot performs a function as the companion of human beings, rather than just as a computing tool. Accordingly, if the tangibles of a robot, including its shape, size, color, and material appeals to users, the size of the Web screen and the screen configuration, both usefulness and user satisfaction can be increased. This means that the perceived usefulness of and user satisfaction with the URC personal robot service can perform a critical function role in the purchase and use of the high-priced URC personal robot. The URC personal robot service offers much smarter and more varied applications, content, and services when connected to the wireless Internet. In addition, the URC personal robot should move quite freely at home and communicate rich and deep emotion with people through a choice of motions, including dancing, winking, smiling, and crying. These functions of the robot terminal, which is the differentiated quality unique to the robot service, will constitute the major precedent variables that affect usefulness and user satisfaction. Therefore, the hypothesis regarding the relationship among service quality, perceived usefulness, and user satisfaction as to the URC personal robot can be asserted as follows:

H4: The service quality of the URC personal robot is positively related to its perceived usefulness.

H5: The service quality of the URC personal robot is positively related to user satisfaction.

\subsection{System Quality, Perceived Usefulness, and User Satisfaction}

System quality refers to the measurement of the information processing system itself (DeLone \& McLean, 1992), and is defined as the processing characteristic of IS. Seddon (1997) previously asserted that system quality is the result of the total consideration of consistency of the user interface, ease of use, documentation quality, program code quality, and maintenance quality. Additionally, in a variety of previous studies, the factors of system quality such as reliability, availability, and response time of IT hardware, communications, and operating systems have been shown to exert a sizeable impact on IS performance (Hamilton \& Chervany, 1981; Kriebel \& Raviv, 1980). Delone and McLean (2004) selected usefulness, usability, responsiveness, reliability and flexibility as the major system quality factors in a number of studies conducted over the past two decades concerning the adoption and success of e-commerce (Liu \& Arnett 2000; Lin \& Lu, 2000; Molla \& Licker 2001; Palmer 2002; Spiller \& Lohse 1998). They also presented usability, availability, reliability, adaptability and response time (e.g., download time) as the crucial aspects of system quality in the acceptance of Internet-based e-commerce systems.

Generally, system quality has been demonstrated to influence the acceptance and adoption of IS and Internet/Web services, mediated by usefulness and user satisfaction. This means that when the system quality of IS and Internet/Web is good, users tend to perceive it as more useful, believing that it can improve their productivity or efficiency and evidencing a positive attitude toward systems with higher levels of user satisfaction. Recently, Byrd et al. (2006) confirmed that system quality is one of the key predictors of usefulness and, furthermore, the system can help to process jobs more efficiently and reduce the operation cost of an organization after the system user has perceived its usefulness. Lin and $\mathrm{Lu}$ (2000) held that IS quality was composed of information quality, response time, and system accessibility and that, among them, response time is the precedent factor of perceived usefulness. Negasha et al. (2003) asserted that the system design that embraced all the system features is critical in enhancing user satisfaction. He has confirmed that interactivity and accessibility are the major system quality factors in designing a web-based customer supporting system, and that those two factors are the most powerful predictor variables of user satisfaction.

As the URC personal robot service also offers information and services that users desire through a variety of information processing capabilities and procedures such as other IS or Internet/Web services, the system quality can be considered to be the determining factor of perceived usefulness and satisfaction. As users tend to believe that the URC personal robot possesses more intelligent information processing features, they tend to expect a great deal more from the system quality of the URC personal robot service. Therefore, system qualities such as stability, accessibility, availability, response speed, and reliability for the URC personal robot service will considerably influence the perceived usefulness and user satisfaction.

On the basis of the above discussion, the hypothesis concerning the relationship among system quality, usefulness, and user satisfaction with the URC personal robot can be asserted as follows:

H6: The system quality of the URC personal robot is positively related to its perceived usefulness.

H7: The system quality of the URC personal robot is positively related to user satisfaction.

\section{Research Methodology}

\subsection{Measurement Development}

In this study, a total of 30 measurement items were developed for tangibles, responsiveness, assurance, system 
quality, perceived usefulness, user satisfaction, and intention to use on the basis of the service quality and IS research literatures, in an effort to characterize the quality, satisfaction and adoption of a personal robot service. Then, three experts from the academy and industry reviewed the measurement items and excluded three items for perceived usefulness and one item for intention to use, on the grounds that the measurements were repetitive. The pre-test involved 5 respondents, who were asked to comment on the length of the instrument and the wording of the scales. Thus, the instrument has confirmed content validity. In order to measure the remaining 26 items, we use a 5-point Likert scales, ranging from " $1=$ strongly disagree" to " $5=$ strongly agree".

Service quality consists of tangibles, responsiveness and assurance, which can appropriately explain for the characteristics of personal robot service. The tangibles of a personal robot refers to the extent that its physical appearance-namely, size, color, material, weight, design, Web screen size and structure appeals to users (Aladwani \& Palvia, 2002; Barnes \& Vidgen, 2001; Kettinger \& Lee,1994; Negasha et al., 2003; Pitt et al., 1995). The responsiveness of a personal robot refers to the extent that it can help users promptly and provide them with emotional services. The assurance of a robot refers to the extent to which it can convey stable and reliable services (Kettinger \& Lee, 1994). System quality is defined as the processing quality of the URC robot system, and system stability, processing diversity, system availability, reliability, and response time were organized as measurement items, following the example set by Delone and McLean (2004), Seddon and Kiew (1994) and Wang and Liao (2007). Perceived usefulness is defined as the extent to which users believe that they can improve job productivity and the quality of life by using the URC personal robot service. Here, seven measurement items were organized, and these are a reworded version of the item-set developed previously by Davis (1989). User satisfaction is defined as the emotional response of users after they experience the URC robot service- this entailed three measurement items, including overall satisfaction with the URC personal robot service (Landrum et al., 2007; Negasha et al., 2003; Seddon, 1997). Intention to use is defined as the intention of users to use the URC personal robot service. The questions employed for the measurement of this factor attempted to ascertain whether users had intentions to use the service when the robot service is launched (Venkatesh \& Davis, 2000). All items in the questionnaire are provided in Table 1.

Table 1. The initial questionnaire items for URC personal robot service

\begin{tabular}{|c|c|c|}
\hline Construct & Measure & Question \\
\hline \multirow{7}{*}{ Tangibles } & TG1 & URC personal robot has appropriate weight. \\
\hline & TG2 & URC personal robot has appealing size. \\
\hline & TG3 & URC personal robot has appealing color. \\
\hline & TG4 & URC personal robot design looks attractive and modern. \\
\hline & TG5 & URC personal robot has visually appealing materials \\
\hline & TG6 & URC personal robot has the appropriate size of Web screen. \\
\hline & TG7 & URC personal robot has a well-structured Web menu \\
\hline \multirow{2}{*}{ Responsiveness } & RP1 & URC personal robot shows free and exuberant motions (e.g. laughing). \\
\hline & RP2 & URC personal robot has diverse driving methods, which is satisfying. \\
\hline \multirow{2}{*}{ Assurance } & AS1 & URC personal robot provides stable service. \\
\hline & AS2 & The service provided by URC personal robot is quite reliable. \\
\hline \multirow{4}{*}{$\begin{array}{l}\text { System } \\
\text { quality }\end{array}$} & SQ1 & URC personal robot goes wherever I want. \\
\hline & SQ2 & I can gain access to any Website I want to with the use of URC personal robot. \\
\hline & SQ3 & URC personal robot features speedy service processing and short response time. \\
\hline & SQ4 & It is easy to control and use URC personal robot. \\
\hline \multirow{5}{*}{$\begin{array}{l}\text { Perceived } \\
\text { usefulness }\end{array}$} & PU1 & URC personal robot service helps improve my job or educational attainment. \\
\hline & PU2 & URC personal robot offers the services that I need. \\
\hline & PU3 & URC personal robot service helps to make use of my spare time. \\
\hline & PU4 & URC personal robot provides a brand-new service that I have never experienced. \\
\hline & PU5 & $\begin{array}{l}\text { I can search for information easily and in a more diverse way with use of URC } \\
\text { personal robot service. }\end{array}$ \\
\hline
\end{tabular}




\begin{tabular}{|c|c|c|}
\hline & PU6 & I can enjoy more convenient life thanks to URC personal robot service. \\
\hline & PU7 & I have savored a choice of pleasure through URC personal robot service. \\
\hline \multirow{3}{*}{$\begin{array}{l}\text { User } \\
\text { satisfaction }\end{array}$} & US1 & I am generally satisfied with URC personal robot service. \\
\hline & US2 & I am satisfied with the $\mathrm{A} / \mathrm{S}$ of URC personal robot. \\
\hline & US3 & I am satisfied with the homepage of URC personal robot service. \\
\hline Intention to use & IU & $\begin{array}{l}\text { I have the intention to use URC personal robot service when it is commercially } \\
\text { launched. }\end{array}$ \\
\hline
\end{tabular}

\subsection{Data Collection}

The first pilot service offered by the NIA and KT (Korea Telecommunications) to 1000 households was conducted for three months, from November 2006 to March 2007. In April 2007, a survey regarding the robot service was conveyed to all participants in the pilot service. The web-based survey was offered through the URC robot service homepage, which is operated by KT.

In an effort to increase the participation rate, banner ads regarding the survey were inserted in the homepages of NIA, ETRI, KT, and the Robotics Company, which provided the URC robot service; the banners were linked to the survey site. Additionally, e-mail notices were sent to the 1000 households-banner ads linked directly to the survey site were embedded into the e-mails. In cases in which households had not responded to the survey after two weeks, calls were made to induce them to participate in the survey, and the e-mails were resent several times. In order to prevent members of the same household from responding multiple times, we endowed them with ID numbers for respondents.

The questionnaire was composed of basic questions about location, type of wired and wireless Internet, measurement items regarding the quality, usefulness, satisfaction, and intention to use the service, and other related topics.

A total of 747 households sent in responses, of which 490 were accepted as valid responses for further analysis after removing missing items. For the 490 respondents, frequency analysis, reliability and exploratory factor analysis using SPSS 14 software were conducted on the data, and we used the structural equation modeling to test the hypothetical relationships in our research model by LISREL 8.30 software.

The descriptive statistics of the respondents' demographic characteristics were analyzed and presented in Table 2. Of the 490 respondents, $53.5 \%$ were male and $46.5 \%$ were female. $4.7 \%$ were in the $25-29$ age group, $67.6 \%$ were $30-39$ in age, $26.5 \%$ were $40-49$ in age, and $1.2 \%$ were $50-59$ in age. The majority of respondents (95.3\%) were over 30 years old. The occupation of the respondents included professional worker (3.5\%), semi-professional / technical worker (21.8\%), administrative worker $(2.9 \%)$, office worker $(40.2 \%)$, sales rep $(4.3 \%)$, service worker $(0.8 \%)$, production worker $(2.0 \%)$, agriculture / livestock / forestry / fishery worker $(0.2 \%)$, non-employee $(1.4 \%)$ and housewives $(22.9 \%)$. The most distinctive result was the relatively high response rate of housewives, which can be translated into the child- and housewife-friendliness of the URC personal robot service.

Table 2. Demographics of respondents

\begin{tabular}{lll}
\hline Measure & Item & Frequency (\%) \\
\hline \multirow{2}{*}{ Gender } & Male & $262(53.5)$ \\
& Female & $228(46.5)$ \\
& $25-29$ & $23(4.7)$ \\
Age & $30-39$ & $331(67.6)$ \\
& $40-49$ & $130(26.5)$ \\
& $50-59$ & $6(1.2)$ \\
Occupation & Professional worker & $17(3.5)$ \\
& Semi-professional \& technical worker & $107(21.8)$ \\
& Administrative worker & $14(2.9)$ \\
\hline
\end{tabular}


Office worker

Sales representative

Service worker

Production worker

Agriculture/Livestock/Forestry/Fishery worker

Non-employee
$197(40.2)$

$21(4.3)$

$4(0.8)$

$10(2.0)$

$1(0.2)$

7 (1.4)

\section{Research Results}

\subsection{Reliability of Instruments}

The measurement items for the factors presented in this research model were derived on the basis of research into the success and adoption of IS and Internet/Web services. The analysis of Cronbach's alpha and item-to-total correlations was conducted in order to evaluate the internal consistency of all the questions. The alpha coefficients and item-to-total correlations of measurement items for each construct are provided in Table 3.

The item-to-total correlation values were higher than 0.3 , representing an acceptable level of internal consistency and the Cronbach's alpha coefficients ranged from 0.600 to 0.929 . Each item was evaluated individually to ensure item reliability. However, 0.6 is allowed as a minimum level when a newly developed item is included (Nunnally, 1978).

Table 3. Reliability analysis

\begin{tabular}{|c|c|c|c|}
\hline Factors & Item & Item-to- total correlation & Cronbach's alpha \\
\hline \multirow{7}{*}{ Tangibles } & TG1 & 0.424 & \multirow{7}{*}{0.826} \\
\hline & TG2 & 0.643 & \\
\hline & TG3 & 0.605 & \\
\hline & TG4 & 0.669 & \\
\hline & TG5 & 0.667 & \\
\hline & TG6 & 0.498 & \\
\hline & TG7 & 0.522 & \\
\hline \multirow{2}{*}{ Responsiveness } & $\mathrm{RP} 1$ & 0.647 & \multirow{2}{*}{0.785} \\
\hline & $\mathrm{RP} 2$ & 0.647 & \\
\hline \multirow{3}{*}{ Assurance } & AS1 & 0.470 & \multirow{2}{*}{0.638} \\
\hline & AS2 & 0.470 & \\
\hline & SQ1 & 0.426 & \multirow{4}{*}{0.600} \\
\hline \multirow{3}{*}{ System quality } & SQ2 & 0.322 & \\
\hline & SQ3 & 0.490 & \\
\hline & SQ4 & 0.380 & \\
\hline \multirow{7}{*}{ Perceived usefulness } & PU1 & 0.810 & \multirow{7}{*}{0.929} \\
\hline & PU2 & 0.810 & \\
\hline & PU3 & 0.753 & \\
\hline & PU4 & 0.774 & \\
\hline & PU5 & 0.740 & \\
\hline & PU6 & 0.785 & \\
\hline & PU7 & 0.764 & \\
\hline \multirow{3}{*}{ User satisfaction } & US1 & 0.466 & \multirow{3}{*}{0.700} \\
\hline & US2 & 0.532 & \\
\hline & US3 & 0.541 & \\
\hline
\end{tabular}




\subsection{Construct Validity}

Because some newly developed measurement items were employed in this research, we conducted an exploratory factor analysis (EFA) using principal axis factoring extraction with Varimax rotation for all the measurement items designed to measure the multidimensional constructs. However, several items had high loadings on factors to which they were not originally assigned. Therefore, factor loadings suggested reassignment of some items. The reassignment of certain items necessitated the recomputation of alpha values as well as the reexamination of factor structure. This process resulted in the final items of 25 representing five district dimensions and, that is, three quality factors of the URC personal robot service, perceived usefulness, and user satisfaction were district. The alpha values and factor loadings belonging to the 25 -item instrument are summarized in Table 4. As shown in Table 4, three of the original six dimensions; tangibles, perceived usefulness and user satisfaction remained district. The remaining three dimensions; responsiveness, assurance and system quality collapsed into two district dimensions; motion quality and system quality, each consisting of items from the original three dimensions. The reliability of the instruments demonstrates that the Cronbach's alpha values for all constructs, with the exception of system quality, is higher than 0.7. However, 0.6 can be the minimum value when newly developed questions are included (Hair et al., 1998; Nunnally, 1978). The Cronbach's alpha values for system quality are allowed as acceptable level. Therefore, the 25 -item instrument was considered to be ready for further testing with confirmatory factor analysis.

Table 4. Factor loadings

\begin{tabular}{llllll}
\hline Item & $\begin{array}{l}\text { Tangible } \\
\text { quality }\end{array}$ & $\begin{array}{l}\text { Motion } \\
\text { quality }\end{array}$ & $\begin{array}{l}\text { System } \\
\text { quality }\end{array}$ & $\begin{array}{l}\text { Perceived } \\
\text { usefulness }\end{array}$ & $\begin{array}{l}\text { User } \\
\text { satisfaction }\end{array}$ \\
\hline TG1 & 0.581 & 0.073 & 0.296 & 0.097 & -0.166 \\
TG2 & 0.719 & 0.192 & 0.074 & 0.124 & 0.124 \\
TG3 & 0.704 & 0.121 & 0.094 & 0.198 & 0.177 \\
TG4 & 0.737 & 0.203 & 0.040 & 0.217 & 0.121 \\
TG5 & 0.747 & 0.162 & 0.073 & 0.218 & 0.129 \\
TG6 & 0.533 & 0.228 & 0.059 & 0.069 & 0.126 \\
TG7 & 0.402 & 0.373 & 0.107 & 0.272 & 0.276 \\
SQ1 & 0.255 & 0.760 & 0.156 & 0.176 & 0.054 \\
RP1 & 0.260 & 0.734 & 0.073 & 0.259 & 0.154 \\
RP2 & 0.226 & 0.796 & 0.087 & 0.183 & 0.119 \\
SQ4 & 0.243 & 0.575 & 0.211 & 0.281 & 0.216 \\
AS1 & 0.115 & 0.213 & 0.776 & 0.266 & 0.046 \\
SQ2 & 0.105 & -0.030 & 0.477 & 0.049 & 0.164 \\
SQ3 & 0.107 & 0.211 & 0.794 & 0.193 & 0.019 \\
AS2 & 0.169 & 0.210 & 0.427 & 0.392 & 0.157 \\
PU1 & 0.172 & 0.151 & 0.108 & 0.814 & 0.162 \\
PU2 & 0.144 & 0.223 & 0.157 & 0.808 & 0.077 \\
PU3 & 0.199 & 0.097 & 0.089 & 0.781 & 0.079 \\
PU4 & 0.138 & 0.142 & 0.054 & 0.803 & 0.111 \\
PU5 & 0.074 & 0.132 & 0.226 & 0.773 & 0.063 \\
PU6 & 0.162 & 0.153 & 0.129 & 0.802 & 0.042 \\
PU7 & 0.201 & 0.157 & 0.086 & 0.777 & 0.112 \\
US1 & 0.178 & 0.175 & 0.088 & 0.345 & \\
US2 & 0.149 & 0.133 & 0.061 & 0.107 & 0.121 \\
US3 & 0.135 & 0.152 & 0.175 & 0.13 & \\
\hline Cronbach's & 0.826 & 0.839 & 0.686 & 0.929 & \\
alpha & & & & & \\
\hline & & & & 0.753 \\
\hline
\end{tabular}


All the items resulted in the preceding analysis were subjected to confirmatory factor analysis. The goodness-of-fit of the measurement model was evaluated using a variety of indices. The result of the confirmatory factor analysis is provided in Table 5 .

We assessed the overall goodness-of-fit using the chi-square test. The chi-square test assesses the adequacy of hypothesized model in terms of its ability to reflect variance and covariance of the data. Due to its tendency to be sensitive to sample size, other fit statistics were considered in conjunction with the chi-square. For the statistical significance of parameter estimates, $t$-value was used. The results of confirmatory factor analysis revealed chi-square of $750.74(\mathrm{p}<0.01)$, goodness-of-fit index(GFI) of 0.90 , Tucker-Lewis index(TLI) of 0.88 , comparative fit index(CFI) of 0.92 and root mean square error of approximation(RMSEA) of 0.061 . Generally, fit statistics greater than or equal to 0.9 for GFI, TLI, and CFI indicate a good model fit (Mulaik et al., 1989); these indicate that the model did fit well with the observed data. Furthermore, RMSEA values ranging from 0.05 to 0.1 are acceptable (Steiger \& Lind, 1980); therefore, the RMSEA suggested that the model fit was acceptable.

Table 5. Confirmatory factor analysis results

\begin{tabular}{|c|c|c|c|c|c|}
\hline Construct & Item & Standardized loading & t-value & Composite reliability & Fit indices \\
\hline \multirow{8}{*}{$\begin{array}{l}\text { Tangible } \\
\text { quality }\end{array}$} & AQ1 & 0.48 & $10.49^{* * *}$ & \multirow{8}{*}{0.834} & \multirow{25}{*}{$\begin{array}{l}\chi^{2}=750.74, \\
\mathrm{df}=265, p=0.000, \\
\mathrm{GFI}=0.90, \\
\mathrm{TLI}=0.88, \\
\mathrm{CFI}=0.92, \\
\text { RMESA }=0.061\end{array}$} \\
\hline & AQ2 & 0.67 & $15.92^{* * *}$ & & \\
\hline & AQ3 & 0.71 & $17.25^{* * *}$ & & \\
\hline & AQ4 & 0.77 & $18.98^{* * *}$ & & \\
\hline & AQ5 & 0.77 & $19.17^{* * *}$ & & \\
\hline & AQ6 & 0.51 & $11.40^{* * *}$ & & \\
\hline & AQ7 & 0.59 & $13.59^{* * *}$ & & \\
\hline & MQ1 & 0.76 & $18.64^{* * *}$ & & \\
\hline Motion & MQ2 & 0.79 & $19.78^{* * *}$ & \multirow{3}{*}{0.842} & \\
\hline \multirow[t]{3}{*}{ quality } & MQ3 & 0.79 & $19.82^{* * *}$ & & \\
\hline & MQ4 & 0.68 & $16.21^{* * *}$ & & \\
\hline & SQ1 & 0.80 & $19.03^{* * *}$ & \multirow{5}{*}{0.721} & \\
\hline \multirow{4}{*}{$\begin{array}{l}\text { System } \\
\text { quality }\end{array}$} & SQ2 & 0.27 & $5.57^{* * *}$ & & \\
\hline & SQ3 & 0.75 & $17.43^{* * *}$ & & \\
\hline & SQ4 & 0.63 & $14.15^{* * *}$ & & \\
\hline & PU1 & 0.86 & $23.31^{* * *}$ & & \\
\hline \multirow{6}{*}{$\begin{array}{l}\text { Perceived } \\
\text { usefulness }\end{array}$} & PU2 & 0.86 & $23.37^{* * *}$ & \multirow{6}{*}{0.931} & \\
\hline & PU3 & 0.79 & $20.43^{* * *}$ & & \\
\hline & PU4 & 0.80 & $20.92^{* * *}$ & & \\
\hline & PU5 & 0.77 & $19.82^{* * *}$ & & \\
\hline & PU6 & 0.81 & $21.50^{* * *}$ & & \\
\hline & PU7 & 0.79 & $20.74^{* * *}$ & & \\
\hline \multirow{3}{*}{ User satisfaction } & S1 & 0.72 & $15.44^{* * *}$ & \multirow{3}{*}{0.692} & \\
\hline & S2 & 0.61 & $12.84^{* * *}$ & & \\
\hline & S3 & 0.63 & $13.28^{* * *}$ & & \\
\hline
\end{tabular}

Note. ${ }^{* * *} p<0.001$.

We also conducted a test of convergent validity and discriminant validity. For these procedures, the fit of model, statistical significance for each standardized loading, composite reliability (CR), and average variance extracted (AVE) were utilized. All the standardized loadings for the items were significant $(t>1.96)$ and the $C R$ value was higher than 0.7 , as shown in Table 5, which suggests that convergent validity of the scale is satisfied (Anderson \& Gerbing, 1988). 
If the AVE is higher than the square of the correlation coefficient among the constructs, it can be asserted that discriminant validity is satisfied (Fornell \& Larcker, 1981). The result of the test of discriminant validity is provided in Table 6, and the AVE values for each construct are plotted on the diagonal line. The square values of the correlation coefficients were all smaller than the AVE values, which indicate that discriminant validity was satisfied.

Table 6. Discriminant validity analysis results

\begin{tabular}{lcclllll}
\hline Construct & Mean & SD & $\begin{array}{l}\text { Tangible } \\
\text { quality }\end{array}$ & $\begin{array}{l}\text { Motion } \\
\text { quality }\end{array}$ & $\begin{array}{l}\text { System } \\
\text { quality }\end{array}$ & $\begin{array}{l}\text { Perceived } \\
\text { usefulness }\end{array}$ & $\begin{array}{l}\text { User } \\
\text { satisfaction }\end{array}$ \\
\hline 1 & 3.275 & 0.627 & $(0.425)$ & & & & \\
2 & 2.799 & 0.794 & 0.612 & $(0.572)$ & & & \\
3 & 2.736 & 0.716 & 0.441 & 0.487 & $(0.418)$ & & \\
4 & 2.833 & 0.809 & 0.480 & 0.515 & 0.525 & $(0.659)$ & \\
5 & 2.885 & 0.741 & 0.453 & 0.474 & 0.376 & 0.460 & $(0.429)$ \\
\hline
\end{tabular}

Note. All correlations are significant at the 0.01 level. Values in parentheses are AVE.

\subsection{Structural Model}

The structural model was assessed in order to test the hypothesis. The fit of the research model is shown in Figure 1; The chi-square test assesses the adequacy of hypothesized model in terms of its ability to reflect variance and covariance of the data. Due to its tendency to be sensitive to sample size, other fit statistics were considered in conjunction with the chi-square. For the statistical significance of parameter estimates, t-value was used. The results of confirmatory factor analysis revealed chi-square of $7.54(\mathrm{p}>0.05)$, the GFI value is 0.99 , the TLI value is 0.99 and the CFI estimate is 0.99 . Those values exceed the criteria of 0.9 ; and the RMSEA value of 0.052 remained within criteria of 0.1 .

The results of hypothesis testing were as follows:

First, the perceived usefulness $(\beta=0.58, \mathrm{p}<0.01)$ and user satisfaction $(\beta=0.14, \mathrm{p}<0.01)$ with regard to the URC personal robot service evidenced a positive relationship with intention to use. In addition, perceived usefulness positively affected user satisfaction $(\beta=0.22, \mathrm{p}<0.01)$. Therefore, $\mathrm{H} 1, \mathrm{H} 2$, and $\mathrm{H} 3$ were all supported.

Second, the tangible quality $(\beta=0.19, p<0.01)$ and motion quality $(\beta=0.24, p<0.01)$ of the URC personal robot service both positively and significantly affected perceived usefulness. Therefore, $\mathrm{H} 4$ was supported. In addition, tangible quality $(\beta=0.18, \mathrm{p}<0.01)$ and motion quality $(\beta=0.21, \mathrm{p}<0.01)$ were found to be the determinants of user satisfaction. Therefore, $\mathrm{H} 5$ was accepted.

Third, the system quality of the URC personal robot service exerted a significant positive effect on perceived usefulness $(\beta=0.32, \mathrm{p}<0.01)$ and user satisfaction $(\beta=0.08, \mathrm{p}<0.1)$, Thus, H6 and H7 were both supported. The results of hypothesis testing are provided in Figure 1. 


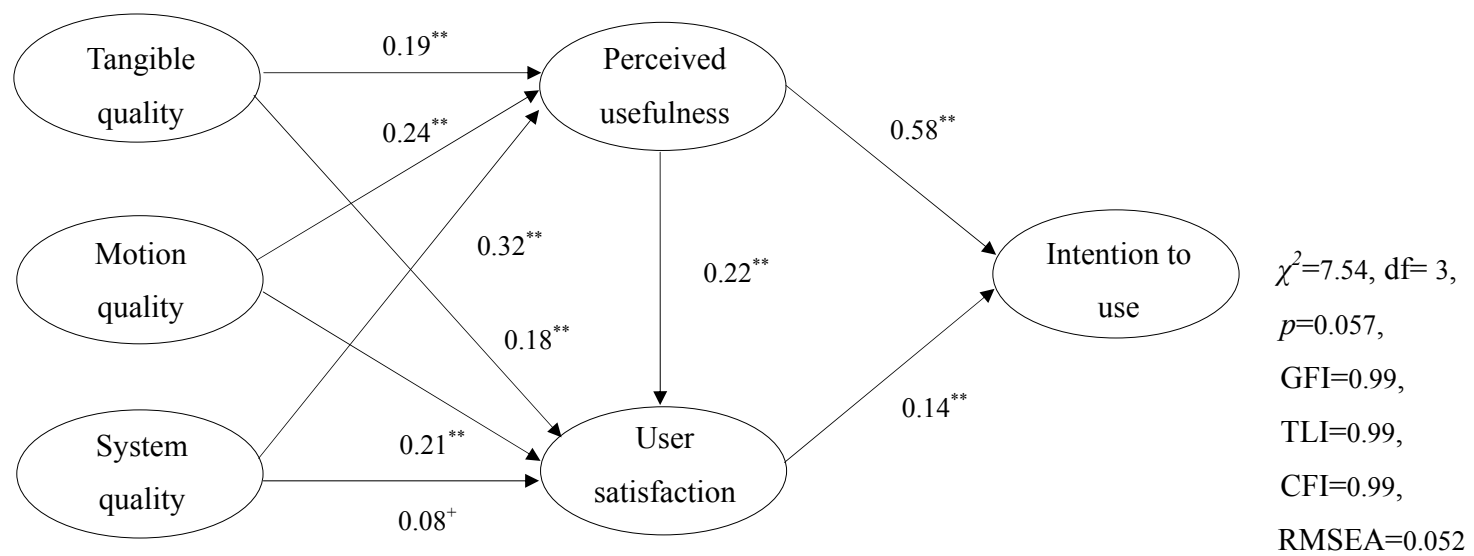

Path significance $(+p<0.1 ; * * p<0.01)$

Figure 1. Results of hypothesis testing

\section{Discussion and Conclusion}

This study proposed a theoretical model to explain the adoption process of the URC personal robot service, and verified it empirically. The study is significant in that the factors and measurement items associated with the usage of the URC personal robot services are adequately applied to the robot service environment. This study showed that tangible quality and motion quality comprise the major service quality dimensions of the URC personal robot services, unlike the case in other IT service sectors. In particular, with regard to tangible quality, the quality information of the robot tangibles are fleshed out with further details, including size, color, and design, unlike the results of traditional research into tangibles. Moreover, the dimensionality and importance of the motion quality were verified as the primary operating characteristics and functions of the robot service. This study also confirmed empirically that perceived usefulness performs a critical function in accepting the URC personal robot service, and that the service quality and system quality are the precedent factors of usefulness and user satisfaction. The results of this study are expected to provide very constructive information to the URC personal robot service providers in product and service development, strategy set-up, marketing planning, and system expansion; all of which will be critical issues in the coming era of commercialized robots.

The summary of the analysis results and implications are as follows:

First, the perceived usefulness and user satisfaction were determined to be the antecedents of the intention to use the URC personal robot service (Bhattacherjee, 2001; Konradta et al., 2006; AL-Gahtani \& King, 1999). For the adoption of the URC personal robot service, the perceived usefulness was identified as the most critical factor that profoundly influences the intention to use the service. This means that users will have the intention to use the commercial URC personal robot service as soon as they perceive its usefulness, and will tend to expect that the URC personal robot will drastically improve job productivity and quality of life through intelligent and human-friendly interaction. Moreover, perceived usefulness has high relevance in user satisfaction, which means that the usefulness of the URC personal robot service will be the central concern in adopting the robot service. Therefore, ways to enhance usefulness and methods by which services can be differentiated should be the overriding consideration when the URC personal robot service is being commercially launched.

Second, service quality (tangible quality and motion quality) was identified as the precedent factor of perceived usefulness and user satisfaction (Landrum et al., 2007; Ahn et al., 2004; Shih, 2004).

The most influential factor was shown to be the tangible quality of the URC personal robot, followed by motion quality. This means that when the robot is physically attractive to users as a companion in their lives, they perceive its higher usefulness and harbor favorable emotions, which in turn raise the user's satisfaction. In this regard, the size, color, material, weight, and design of robots preferred by users should first be explored, and the robot features specifically customized to each user group should be provided. The motion quality, which is the service-performance quality unique to the robot, includes free movements as well as a variety of human-like motions (dancing, winking, crying, laughing, and the like). This means that the motion performance of the robot can provide many useful features, such as pleasure and convenience for users, and can also enhance users' 
satisfaction with the robot service. Meanwhile, the Web appearance evidenced the lowest level of influence on usefulness and user satisfaction. However, improved usefulness and user satisfaction remain major factors, in that the URC robot offers a diverse range of functions and information services via web-based interaction.

Third, the system quality of the URC personal robot service was identified as the major factor in predicting perceived usefulness and user satisfaction (Byrd et al., 2006; Lin \& Lu 2000, Negasha et al., 2003).

The relevance of the relationship between system quality and perceived usefulness was significantly high. In addition, the system quality affected usefulness more profoundly than the service quality factors, which indicates that users place system quality first, as opposed to the tangible quality and motion quality of the robot. The URC personal robot service is a single system composed of the robot platform, network, and URC server. Therefore, users think that job efficiency can be improved, or their lives can be made more convenient when the stability, reliability, response time, and availability of the robot are secured in the context of the entire URC system. Therefore, the robot platform, network, and URC server should have more powerful functions, and their performance should be enhanced.

The limitations in this study are as follows:

One of these limitations involved making the constructs of service quality and system quality more multidimensional, as the URC personal robot service is currently in the pilot service stage, and is evolving within an imperfect service environment. Other service quality dimensions such as empathy and reliability, which have been extensively utilized for traditional research, will require further research to characterize the multidimensionality of the service quality after the commercialization of the service. Measurement items, such as system quality factors, will also require further development, appropriate to the specific terminal of robot. Finally, the common quality factors were derived among the five types of robots that were input to the URC personal robot service in this study. However, the application and function are specialized to each URC personal robot type. Therefore, the service quality dimension that is differentiated by robot type requires additional study in order to identify the relevancy of those dimensions with individual use behavior, and to improve the intention to use the URC personal robot service.

\section{Acknowledgement}

This work was supported by the research grant of the Chungbuk National University in 2013.

\section{References}

Adams, D. A., Nelson, R. R., \& Todd, P. A. (1992). Perceived usefulness, ease of use, and usage of information technology: A replication. MIS Quarterly, 16(2), 227-247. http://dx.doi.org/10.2307/249577

Aladwania, A. M., \& Palvia, P. C. (2002). Developing and validating an instrument for measuring user-perceived $\begin{array}{llll}\text { web quality. Information } \& \text { Management, } & 39(6),\end{array}$ http://dx.doi.org/10.1016/S0378-7206(01)00113-6

Al-Gahtani, S. S., \& King, M. (1999). Attitudes, satisfaction and usage: Factors contributing to each in the acceptance of information technology. Behaviour \& Information Technology, 18(4), 277-297. http://dx.doi.org/10.1080/014492999119020

Anderson, J. C., \& Gerbing, D. W. (1988). Structural equation modeling in practice: A review and recommended two-step approach. Psychological Bulletin, 103(3), 411-423. http://dx.doi.org/10.1037/0033-2909.103.3.411

Ahn, T., Ryu, S., \& Han, I. (2004). The impact of the online and offline features on the user acceptance of Internet shopping malls. Electronic Commerce Research and Applications, 3(4), 405-420. http://dx.doi.org/10.1016/j.elerap.2004.05.001

Barnes, S. J., \& Vidgen, R. (2001). An evaluation of cyber-bookshops: the WebQual method. International Journal of Electronic Commerce, 6(1), 11-30. http://dx.doi.org/10.1108/10662249810217768

Bell, H., \& Tang, N. (1998). The effectiveness of commercial Internet web sites: A user's perspective. Internet Research, 8(3), 219-228.

Bhattacherjee, A. (2001). An empirical analysis of the antecedents of electronic commerce service continuance. Decision Support Systems, 32(2), 201-214. http://dx.doi.org/10.1016/S0167-9236(01)00111-7

Byrd, T. A., Thrasher, E. H., Langc, T., \& Davidson, N. W. (2006). A process-oriented perspective of IS success: Examining the impact of IS on operational cost. Omega, 34(5), 448-460. http://dx.doi.org/10.1016/j.omega.2005.01.012

Byun, S. I. (2006). IPv6 based URC service robot. National Information Society Agency. 
Cenfetelli, R. T., Benbasat, I., \& Al-Natour, S. (2005). Information technology mediated customer service: A functional perspective. Twenty-Sixth International Conference on Information Systems, 11-25.

Chung, J. S. (2004). IT 839 strategy and u-Korea service. National Information Society Agency.

Davis, F. (1989). Perceived usefulness, perceived ease of use, and user acceptance of information technology. MIS Quarterly, 13(3), 318-340. http://dx.doi.org/10.2307/249008

Davis, F. D., Bagozzi, R. P., \& Warshaw, P. R. (1989). User acceptance of computer technology: A comparison of two theoretical models. Management Science, 35(8), 982-1003. http://dx.doi.org/10.1287/mnsc.35.8.982

Delone, W. H., \& Mclean, E. R., (1992). Information systems success: The quest for the dependent variable. Information Systems Research, 3(1), 60-95. http://dx.doi.org/10.1287/isre.3.1.60

Delone, W. H., \& Mclean, E. R., (2004). Measuring e-Commerce success: Applying the DeLone \& McLean information systems success model. International Journal of Electronic Commerce, 9(1), 31-47.

Delone, W. H., \& Mclean, E. R. (2003). The DeLone and McLean model of information systems success: A ten-year update. Journal of Management Information Systems, 19(4), 9-30.

Dishaw, M. T., \& Strong, D. M. (1998). Supporting software maintenance with software engineering tools: A computed task-technology fit analysis. Journal of Systems and Software, 44(2), 107-120. http://dx.doi.org/10.1016/S0164-1212(98)10048-1

Doll, W. J., \& Torkzadeh, G. (1988). The measurement of end-user computing satisfaction. MIS Quarterly, 12(2), 259-275. http://dx.doi.org/10.2307/248851

Etezadi-Amoli, J., \& Farhoomand, A. F. (1996). A structural model of end user computing satisfaction and user performance. Information \& Management, 30(2), 65-73. http://dx.doi.org/10.1016/0378-7206(95)00052-6

Fornell, C., \& Larker, D. F. (1981). Evaluating structural equation models with unobservable variables and measurement error. Journal of Marketing Research, 18(1), 39-50. http://dx.doi.org/10.2307/3151312

Garvin, D. A. (1987). Competing on the eight dimensions of quality. Harvard Business Review, Nov. Dec., 101-109.

Gelderman, M. (1998).The relation between user satisfaction, usage of information systems and performance. Information \& Management, 34(1), 1-11. http://dx.doi.org/10.1016/S0378-7206(98)00044-5

Grönroos, C. (1984). A service quality model and its marketing implications. European Journal of Marketing, 18(4), 36-44. http://dx.doi.org/10.1108/EUM0000000004784

Hair, J. F., Anderson, R. E, Tatham, R. L., \& Black, W. C. (1998). Multivariate Data Analysis. Englewood Cliffs, NJ :Prentice-Hall.

Hamilton, S., \& Chervany, N. (1981). Evaluating information system effectiveness. Part 1, Comparing evaluation approaches. MIS Quarterly, 5(3), 55-69. http://dx.doi.org/10.2307/249291

Hsu, M. H., \& Chiu, C.M. (2004). A predicting electronic service continuance with a decomposed theory of planned behavior. Behaviour \& Information Technology, 23(5), 359-373. http://dx.doi.org/10.1080/01449290410001669969

Huizingh, E. K. (2000). The content and design of web sites: an empirical study. Information \& Management, 37(3), 123-134. http://dx.doi.org/10.1016/S0378-7206(99)00044-0

I4u news. (2005). Ubiquitous robotic companion. Retrieved from http://www.i4u.com/article4450.html

Igbaria, M., \& Tan, M. (1997). The consequences of the information technology acceptance on subsequent $\begin{array}{llll}\text { individual performance. Information } \& \text { Management, } & 32(3), & 113-121 .\end{array}$ http://dx.doi.org/10.1016/S0378-7206(97)00006-2

Iwaarden, J. V., Wielea, T. V., Ballb, L., \& Millen, R. (2004). Perceptions about the quality of web sites: A survey amongst students at Northeastern University and Erasmus University. Information \& Management, 41(8), 947-959. http://dx.doi.org/10.1016/j.im.2003.10.002

Jiang, J. J., Kleing, G., \& Crampton, S. M. (2000). A note on SERVQUAL reliability and validity in information system service quality measurement. Decision Sciences, 31(3), 725-744. http://dx.doi.org/10.1111/j.1540-5915.2000.tb00940.x

Karahanna, E., Straub, D. W., \& Chervany, N. L. (1999). Information technology adoption across time. MIS Quarterly, 23(2), 183-213. http://dx.doi.org/10.2307/249751 
Kettinger, W. J., \& Lee, C. C. (1994). Perceived service quality and user satisfaction with the information $\begin{array}{llll}\text { services function. } & \text { Decision } & \text { 737-766. }\end{array}$ http://dx.doi.org/10.1111/j.1540-5915.1994.tb01868.x

Kim, B. G., Park, S. C., \& Lee, K. J. (2007). A structural equation modeling of the Internet acceptance in Korea. $\begin{array}{llll}\text { Electronic Commerce Research and } & \text { 425-432. }\end{array}$ http://dx.doi.org/10.1016/j.elerap.2006.08.005

Konradta, U., Christophersena, T., \& Schaeffer-Kuelzb, U. (2006). Predicting user satisfaction, strain and system usage of employee self-services. International Journal of Human-Computer Studies, 64(11), 1141-1153. http://dx.doi.org/10.1016/j.ijhcs.2006.07.001

Korea. Net. (2007). Retrieved from http://www.korea.net/News/News/LangView.asp?serial_no=2007 0104031\&lang_no=1\&part

Kriebel, C., \& Raviv, A. (1980). An economics approach to modeling the productivity of computer systems. Management Science, 26(3), 297-311. http://dx.doi.org/10.1287/mnsc.26.3.297

Landrum, H., Prybutok, V. R., \& Zhang, X. (2007). A comparison of Magal's service quality instrument with SERVPERF. Information \& Management, 44(1), 104-113. http://dx.doi.org/10.1016/j.im.2006.11.002

Lassar, W. M., Manolis, C., \& Winsor, R. D. (2000). Service quality perspectives and satisfaction in private banking. Journal of Service Marketing, 13(3), 244-271. http://dx.doi.org/10.1108/08876040010327248

Lee, G., \& Lin, H. (2005). Customer perceptions of e-service quality in online shopping. International Journal of Retail \& Distribution Management, 33(2), 161-176.

Li, E. Y. (1997). Perceived importance of information system success factors: A meta analysis of group differences. Information \& Management, 32(1), 15-28. http://dx.doi.org/10.1016/S0378-7206(97)00005-0

Lin, J. C. C., \& Lu, H. (2000). Towards an understanding of the behavioural intention to use a web site. International Journal of Information Management, 20(3), 197-208. http://dx.doi.org/10.1016/S0268-4012(00)00005-0

Liu, C., \& Arnett, K. (2000). Exploring the factors associated with Web site success in the context of electronic commerce. Information \& Management, 38(1), 23-33. http://dx.doi.org/10.1016/S0378-7206(00)00049-5

Lucas, H. C., \& Spitler, V. K. (1999). Technology use and performance: A field study of broker workstations. Decision Sciences, 30(2), 291-311. http://dx.doi.org/10.1111/j.1540-5915.1999.tb01611.x

Magal, S. R. (1991). A model for evaluating information center success. Journal of Management Information Systems, 8(1), 91-106.

Mathieson, K. (1991). Predicting user intentions: comparing the technology acceptance model with the theory of planned behavior. Information Systems Research, 2(3), 173-191. http://dx.doi.org/10.1287/isre.2.3.173

Mcknight, D. H., Choudhury, V., \& Kacmar, C. (2002). Developing and validating trust measures for E-Commerce: an integrative typology. Information Systems Research, 13(3), 334-359. http://dx.doi.org/10.1287/isre.13.3.334.81

Molla, A., \& Licker, P. S. (2002). E-commerce systems success: An attempt to extend and respecify the DeLone and McLean model of IS success. Journal of Electronic Commerce Research, 2(4), 1-11.

Mulaik, S.A., James, L. R., Van Alstine, J., Bonnett, N., Lind, S., \& Stilwell, D. (1989). Evaluation of goodness of fit indices for structural equation models. Psychological Bulletin, 105(3), 430-445. http://dx.doi.org/10.1037/0033-2909.105.3.430

Negasha, S., Ryanb, T., \& Igbaria, M. (2003). Quality and effectiveness in Web-based customer support systems. Information \& Management, 40(8), 757-768. http://dx.doi.org/10.1016/S0378-7206(02)00101-5

Nunnally, J. (1978). Psychometric Theory. New York: Mc Graw-Hill.

O’Neill, M., Wright, C., \& Fitz, F. (2001). Quality evaluation in on-line service environments: An application of the importance-performance measurement technique. Managing Service Quality, 11(6), 402-417. http://dx.doi.org/10.1108/EUM0000000006519

Palmer, J. W. (2002). Web site usability, design, and performance metrics. Information Systems Research, 13(2), 151-167. http://dx.doi.org/10.1287/isre.13.2.151.88 
Parasuraman, A., Berry, L. L., \& Zeithaml, V. A. (1988). SERVQUAL: A multiple-item scale for measuring consumer perceptions of service. Journal of Retailing, 64(1), 12-40.

Parasuraman, A., Zeithaml, V., \& Malhotra, A. (2005). E-S-Qual: A multiple-item scale for assessing electronic service quality. Journal of Service Research, 7(3), 213-233. http://dx.doi.org/10.1177/1094670504271156

Pitt, L. F., Watson, R. T., \& Kavan, C. B. (1995). Service quality: a measure of information systems effectiveness. MIS Quarterly, 19(2), 173-187. http://dx.doi.org/10.2307/249687

Rai, A., Lang, S. S., \& Welker, R. B. (2002). Assessing the validity of IS success models: An empirical test and theoretical analysis. Information Systems Research, 13(1), 50-69. http://dx.doi.org/10.1287/isre.13.1.50.96

Robledo, M. A. (2001). Measuring and managing service quality: integrating customer expectations. Managing Service Quality, 11(1), 22-31. http://dx.doi.org/10.1108/09604520110379472

Seddon, P. B. (1997). A respecification and extension of the DeLone and McLean model of IS success. Information Systems Research, 8(3), 240-253. http://dx.doi.org/10.1287/isre.8.3.240

Seddon, P. B., \& Kiew, M. (1994). A partial test and development of DeLone and McLean's model of IS success. Proceedings of the Fifteenth International Conference on Information Systems, Vancouver, Canada, 99-110.

Shih, H. P. (2004). An empirical study on predicting user acceptance, of e-shopping on the Web. Information \& Management, 41(3), 351-368. http://dx.doi.org/10.1016/S0378-7206(03)00079-X

Spiller, P., \& Lohse, G. (1998). A classification of Internet retail stores. International Journal of Electronic Commerce, 2(2), 29-56.

Steiger, J. H., \& Lind, J. C. (1980). Statistically based tests for the number of common factors. IOWA City, IA: paper presented at the annual meeting of the Psychometric Society.

Sullivan, J. R., \& Walstrom, K. A. (2001). Consumer perspectives on service quality of electronic commerce web sites. Journal of Computer Information Systems, 41(3), 8-14.

Taylor, S., \& Todd, P. A. (1995). Understanding information technology usage: a test of competing models. Information Systems Research, 6(2), 144-176. http://dx.doi.org/10.1287/isre.6.2.144

Van Dyke, T. P., Prybutok, V. R., \& Kappleman, L. A. (1999). Cautions on the use of the SERVQUL measure to assess the quality of information systems services. Decision Sciences, 30(3), 877-891. http://dx.doi.org/10.1111/j.1540-5915.1999.tb00911.x

Venkatesh, V., \& Davis, F. D. (2000). A theoretical extension of the technology acceptance model: Four $\begin{array}{lllll}\text { longitudinal field } & \text { studies. }\end{array}$ http://dx.doi.org/10.1287/mnsc.46.2.186.11926

Venkatesh, V., \& Morris, M. G. (2000). Why don’t men ever stop to ask for directions? Gender, social influence, and their role in technology acceptance and usage behavior. MIS Quarterly, 24(1), 115-139. http://dx.doi.org/10.2307/3250981

Wang, Y. S., \& Liao, Y. W. (2007). The conceptualization and measurement of $\mathrm{m}$-commerce user satisfaction. Computers in Human Behavior, 23(1), 381-398. http://dx.doi.org/10.1016/j.chb.2004.10.017

Wilkin, C., \& Hewitt, B. (1999). Quality in a respecification of DeLone and McLean's IS success model, In M. Khozrowpour (Ed.), Proceedings of 1999 IRMA International Conference Hershey (pp. 663-672). PA: Idea Group Publishing.

Yoon, Y., Guimaraes, T., \& O’Neal, Q. (1995). Exploring the factors associated with expert systems success. MIS Quarterly, 19(1), 83-106. http://dx.doi.org/10.2307/249712

\section{Copyrights}

Copyright for this article is retained by the author(s), with first publication rights granted to the journal.

This is an open-access article distributed under the terms and conditions of the Creative Commons Attribution license (http://creativecommons.org/licenses/by/3.0/). 